EMBRYARIDDLE
Aeronautical University

SCHOLARLY COMMONS

\section{International Journal of Aviation,} Aeronautics, and Aerospace

\title{
Fatigue Identification and Management in Flight Training: An Investigation of Collegiate Aviation Pilots
}

\author{
FLAVIO A. COIMBRA MENDONCA MR \\ Purdue University, coimbraf@erau.edu \\ Julius Keller \\ Purdue University, keller64@purdue.edu \\ Chientsung Lu \\ Purdue University, ctlu@purdue.edu
}

Follow this and additional works at: https://commons.erau.edu/ijaaa

Part of the Aviation and Space Education Commons, Aviation Safety and Security Commons, and the Education Commons

\section{Scholarly Commons Citation}

MENDONCA, F. A., Keller, J., \& Lu, C. (2019). Fatigue Identification and Management in Flight Training: An Investigation of Collegiate Aviation Pilots. International Journal of Aviation, Aeronautics, and Aerospace, 6(5). https://doi.org/10.15394/ijaaa.2019.1365

This Article is brought to you for free and open access by the Journals at Scholarly Commons. It has been accepted for inclusion in International Journal of Aviation, Aeronautics, and Aerospace by an authorized administrator of Scholarly Commons. For more information, please contact commons@erau.edu. 


\title{
Fatigue Identification and Management in Flight Training: An Investigation of Collegiate Aviation Pilots
}

\author{
Flavio A. C. Mendonca - Ph.D. \\ FMENDONC@PURDUE.EDU - 7654966155 \\ Julius Keller - Ph.D. \\ KELLER64@PURDUE.EDU - 4949969 \\ Chien-tsung Lu - Ph.D. \\ CTLU@PURDUE.EDU - 7654946387
}

Objective: The purpose of this study was to evaluate collegiate aviation students' self-awareness of their fatigue issues; to investigate possible causes of fatigue afflicting collegiate aviation students; and to investigate the collegiate aviation students' lifestyle and perceptions of personal solutions to fatigue.

Background: Pilot fatigue is a significant safety hazard in aviation operations. Several factors can contribute to fatigue, including inadequate sleep, long work hours, and inadequate nutritional habits. Some factors, such as social and academic activities, could be unique for Title 14 Code of Federal Regulations (CFR) Part 141 collegiate aviation pilots. Previous studies have addressed fatigue in commercial and military aviation. However, few studies have targeted collegiate aviation students.

Method: An online survey questionnaire was utilized to investigate collegiate aviation students' self-awareness of their fatigue issues; the possible causes of fatigue afflicting those students; and their lifestyle. The population for this study consisted of a subset of the GA community, flight instructors and students from an accredited 14 CFR Part 141 four-year degree-awarding university in the Midwestern region of the United States.

Results: Findings indicated that fatigue has played a role during flight training. Pilots had, for example overlooked mistakes because of fatigue. Responses also suggested decrements in alertness and cognitive functions as a result of fatigue.

Conclusion: Fatigue is a safety hazard in a collegiate environment that needs addressing. Systematic fatigue education and training, better lifestyle practices, effective workload management, and even a prescriptive approach could significantly enhance aviation safety and the well-being of student pilots. 


\section{Introduction}

Pilot fatigue is a significant hazard to aviation operations that is commonplace in both civilian and military flight operations (Caldwell et al., 2009; Marcus \& Rosekind, 2017). A query using the National Transportation Safety Board (NTSB) database yielded 37 accidents involving Code of Federal Regulation Part 91, general aviation operators, from January 2000 through December of 2018, in which pilot fatigue was a contributing factor. According to Dawson and McCulloch (2005), indicating factors for pilot fatigue may be difficult to ascertain. Fatigue may have been an important latent condition for many of the approximately 30,032 general aviation accidents since January of 2000 (NTSB, 2009). Additionally, events that barely missed a detrimental situation due to fatigue, often times go unnoticed and or unreported. Fatigue is generally the product of one or more factors that include inadequate food and/or fluid intake, mental workload, physical fatigue, and disrupted or lack of sleep (Stokes \& Kite, 2016). Adequate sleep is the most efficient strategy to mitigate fatigue. However, several other strategies can assist in mitigating the risk of aircraft accidents due to the insidious effects of pilot fatigue (Dawson, Clegget, Thompson, \& Thomas, 2017; Gander et al., 2013). The international Civil Aviation Organization (ICAO) Standards and Recommended Practices (SARPs) applied to flight crews generally target commercial flight operations (ICAO, 2016). Similarly, the Federal Aviation Administration (FAA) fatigue management regulations and policies generally address commercial pilots' flight, duty and rest rules within Federal Aviation Regulation Part 117. The most significant duty time regulations in Part 91 operations is that flight instructor is limited to eight hours of flying per 24 hour time period. Extant research studies have focused on fatigue identification and management within the commercial and/or military aviation environments (Caldwell et al., 2009; Gawron, 2016; Marcus \& Rosekind, 2017; Sieberichs \& Kluge, 2016). This body of knowledge has certainly reduced the risk of mishaps due to flight crew's fatigue. However, little to nothing has been done to investigate the fatigue identification and mitigation strategies by general aviation pilots. Within the collegiate aviation environment, pilots face much different challenges than the commercial or military sector. Therefore, it is prudent for general aviation researchers to gain a clearer understanding of the issues. The next section will highlight existing knowledge pertaining to fatigue and discuss causes, effects as well as mitigation strategies.

\section{Literature Review}

Managing fatigue is an important component of the aviation system (Caldwell et al., 2009; ICAO, 2016). A literature review of previous research and the ICAO safety management systems (SMS) requirements and best practices addressing fatigue in aviation, and aeronautical decision-making (ADM) was conducted. This section discusses how fatigue can negatively impact aviation safety, and how GA pilots can identify signs of fatigue. Most importantly, it explores possible strategies by GA pilots that could be implemented to mitigate the risk of fatigue in aviation.

\section{Fatigue and Aviation Safety}

Fatigue is a ubiquitous and normal aspect of life (Salazar, nd). For many people fatigue is

only a disturbance that can be solved with a good night of sleep, a break in a specific activity that 
brought it on, or even a short nap. In these cases, fatigue will rarely lead to undesired consequences. However, improperly identified and managed fatigue could lead to disastrous consequences in safety-related activities, such as aviation (Caldwell et al., 2009). Fatigue is a multidimensional construct, associated with multifaceted life and work factors, including the safety culture of the organization (Avers \& Johnson, 2011; Fletcher, Hooper, Dunican, \& Kogi, 2015), for which no single-mitigation strategy will be effective (Caldwell et al., 2009).

According to Sieberich and Kluge (2016), fatigue can be subdivided in emotional, mental, and physical. In addition, its effects vary among different individuals. ICAO (2012) defines fatigue as

a physiological state of reduced mental or physical performance capability resulting from sleep loss or extended wakefulness, circadian phase, or workload (mental and/or physical activity) that can impair a crew member's alertness and ability to safely operate an aircraft or perform safety-related duties (p. xii).

Several studies have indicated a relationship between increasing fatigue and increments of human-error rates, decrements in cognitive functions, reduced situational awareness and effective performance (Dawson \& McCulloch, 2005; Honn, 2017; Roach et al., 2017), and impaired neurobehavioral performance (Greeley et al., 2013). Fatigue, from a safety standpoint, poses a serious threat to pilots, passengers, and aircraft (Fletcher et al., 2015). A more detailed query using the NSTB database from January 2000 through December of 2018 yielded 30,032 aircraft accidents involving GA aircraft (NTSB, 2009). In 32 of those safety occurrences the NTSB suggested pilot's fatigue was or may have been a contributing factor to the accident. As a comparison, during the same period there were 627 accidents involving Part 121 operators that were investigated by the NTSB. The Board suggested that fatigue may have played a role in 13 safety events. The issue is important enough for the NTSB to add fatigue to the 2019-2020 most wanted list to prevent accidents (NTSB, 2019a). This is an important step for the complex issue.

Safety investigators are generally not well suited to determine fatigue was a contributing factor to a specific accident (Avers \& Johnson, 2011). In fact, there is no simple formula to ensure the flight crew's fatigue was a causal factor to a mishap (ICAO, 2016; Wilson, 2015). Human factors such as physiology, psychology, ageing, motivation, human limitations, and incapacitation are frequently relatively intangible, but pertinent variables during the investigation process. Nonetheless, each factor alone, or usually in different combinations, can lead to fatigue. Moreover, people respond differently to fatigue or to the elements that can increase fatigue. For instance, there are major differences in the way pilots generally respond to sleep loss, jet lag, and circadian rhythms (Caldwell et al., 2009), inherent elements of the aviation system known to lead to or increase fatigue (ICAO, 2012). During certain investigation processes, the investigator will depend upon the report of witnesses to establish fatigue as a causal factor (ICAO, 2003). The use of fatigue identification models can be useful during the investigation process (Dawson \& McCulloch, 2005). According to ICAO (2016), to establish that fatigue was a contributing factor to a safety event, it should be demonstrated that:

1. The pilot or flight crew was in a fatigued state; 
2. The pilot or flight crew took particular decisions and/or actions that contributed to the undesired outcomes; and

3. Those decisions and/or actions are consistent with the type of behavior expected of a fatigued pilot or flight crew (ICAO, 2016, p. 4-15).

ICAO (2016) provides guidance and checklists on the investigation of fatigue in aviation safety events that could assist in establishing the link between the unsafe acts by the flight crews and their unsafe acts that contributed to the occurrence. However, despite useful, models, guidance, and checklists cannot tell investigators everything about the individual human behavior prior to the accident, and other human-factors that could have contributed to fatigue. According to Goode (2003), the NTSB has been reluctant to establish fatigue or elements that could lead to impaired performance by pilots as a contributing factor to aircraft accidents.

ICAO members States are not required, in accordance with the ICAO Standards and Recommended Practices (SARPs) laid out in Annex 13 - Aircraft Accident and Incident Investigation, to investigate the majority of incidents and near-misses (ICAO, 2016). Thus, many aircraft incidents and near-misses are not deeply investigated or even investigated at all. Considering there are more aircraft incidents and near-misses than aircraft accidents (Heinrich \& Grannis, 1959; NTSB, 2019b), one could assume that the number of safety occurrences (other than aircraft accidents) due to pilot's fatigue to be much higher than the official statistics by the NTSB database. Most importantly, one could expect the number of missed opportunities to identify flight crews' fatigue-related risk to be high.

\section{Causes and Symptoms of Fatigue in Aviation}

Despite previous studies, the impact of pilots' fatigue in aviation safety is frequently underestimated (Salazar, nd; Sieberichs \& Kluge, 2016; Stokes \& Kite, 2016). The deleterious effect of fatigue on aviation safety is ubiquitous and well known, though. Insufficient and/or inadequate sleep are the most influencing factors on fatigue (Caldwell, 2005; Czeisler et al., 2016; Dawson et al., 2017; Tefft, 2016). Shift work, travel across time zones, and prolonged wakefulness can compromise sleep. Adequate sleep is paramount for the restoration of the brain and body (Hirskowitz et al., 2015). Fatigue is mostly impacted by time of last major sleep, time of the day, and time on-duty (Caldwell, 2005; ICAO, 2012). According to the Civil Aviation Safety Authority (CASA) of the Australia government (CASA, 2012), factors not directly associated with sleep could have an impact of fatigue level of flight crews, such as emotional strain, inadequate food and/or fluid intake, and mental workload. A study by Dawson and Reid (1997) and by Tefft (2016) indicated that moderate levels of fatigue could produce higher levels of impairment than the proscribed level of alcohol intoxication. Studies by Caldwell (2001, 2005) also suggested decrements in human cognitive functions due to fatigue, all vital in the flight deck, similar to performance with high-blood alcohol concentrations. In different words, moderate levels of fatigue can cause a pilot to be impaired as if they had blood alcohol concentrations of $0.05-0.08 \%$.

According to the US National Safety Council (NSC), fatigue is a multidimensionalphenomena associated with physiological sleep needs and internal biological rhythms (NSC, 
2019). Several other factors can directly or indirectly increase aviators' fatigue, among them workload, extended duty periods, early departures and/or late arrivals, non-standard working hours, trans-meridian crossings (Caldwell, 2005), multiple flight legs, restricted sleep opportunities, nutritional deficiencies (Avers \& Johnson, 2011), and family and social factors (Lee \& Kim, 2018). A study by Powell, Spencer, Holland, Broadbent, and Petrie (2007) identified duty length and the number of sectors flown, as well as early departures as important factors influencing fatigue by air carrier' pilots. A project by Powell, Spencer, Holland, and Petrie (2008) identified that the length of duty, number of sectors, and time of the day (circadian rhythms) as significant contributors of fatigue. Honn, Satterfield, McCauley, and Caldwell (2016) conducted a study to identify whether the number of sectors affects fatigue among commercial pilots. Duty start times and durations, among other variables that impact fatigue, were held constant. Findings suggest higher levels of fatigue among pilots involved in a multisegment duty than those involved in a single-segment duty day. Gander et al. (2013) conducted a study to identify whether flight crew's fatigue was higher during ultra-long range (ULR) flights than long range flights. Participants were Delta Airlines pilots. Despite some limitations to this study, findings suggested there was no significant difference between long range flights and ULR. Nevertheless, researchers posited that only a combination of few factors will negatively impact the levels of fatigue by each pilot.

A long day or night of mental stimulation, such as working with a course assignment or preparing for an exam, can be extremely fatiguing (CASA, 2012; Keller, Mendonca, Levin, \& Teo, 2019). As such, these activities could reduce the level of safety in the flight deck of an aircraft. The researchers of the current study recommend reading the ICAO (2016) and CASA (2012) materials for further information about factors that could lead or increase fatigue in the flight deck of an aircraft. Nonetheless, as mentioned by Caldwell (2005) and by the NSC (2019), humans are not well equipped to operate efficiently on the demanding 24/7 schedules associated with flight activities.

Defining and especially managing fatigue in the flight deck is extremely difficult due to the large variability of factors causing or contributing to fatigue (Gander et al., 2013; NSC, 2019; Salazar, n.d.). From a physiological standpoint, research has demonstrated that "fatigue impairs central nervous system" (Caldwell et al., 2009, p. 30). As previously noted, fatigue has been associated with decrements in cognitive functions (Caldwell, 2001, 2005; Dawson et al., 2017; NSC, 2019). Cognitive slowness, concentration difficulties, lethargy, and sleepiness are also symptoms of fatigue (Petrie \& Dawson, 1997). According to CASA (2012), symptoms of fatigue in the cockpit of an aircraft includes reduced attention and situational awareness, difficulty to concentrate, increased omissions and carelessness, muddled reasoning, and faulty short-term memory. In summary, fatigue severely decrease the pilots' abilities to carry out tasks requiring concentration, manual dexterity, complex thinking, and "higher-order intellectual processing" (Salazar, n.d., p. 2). The symptoms of fatigue could be grouped into four broader concepts: cognitive dysfunction (e.g., reduced situational awareness; forgetfulness); somatic symptoms (e.g., headaches; sore muscles); subjective tiredness states (e.g., sleepy; low energy); and behavioral changes (e.g., easily irritated; feeling of frustration) (Petrie \& Dawson, 1997).

Fatigue in the flight deck has been primarily managed through a prescriptive regulatory approach (Dawson et al., 2017; Gander et al., 2013; ICAO, 2016). Although an important 
strategy to mitigate fatigue, prescriptive regulatory limits generally fail to incorporate empirical data addressing the interactions between circadian rhythms and sleep (Caldwell et al., 2009). For example, standards addressing fatigue could at some level be adequate for physical fatigue but might not be appropriate for mental fatigue (Dawson \& McCullough, 2005). Yet, such regulatory approach may assume that compliance would ensure an acceptable (or minimum) level of safety. Prescriptive duty limitations represent a somewhat simplistic strategy to mitigate the risk of accidents due to fatigue. Moreover, they represent a single defensive strategy. Regulations could be adequate for some types of aviation operations; however, "they are a one-size-fits-all approach that does not take into account operational differences or differences among crew members" (ICAO, 2016, p. 1-2). Solutions to the fatigue issue in the complex aviation system are not straightforward. Considering fatigue is a multidimensional construct, associated with multifaceted factors, several not related to the flight itself (e.g., regular physical activities), a multifaceted approach to mitigating fatigue is also vital (Fletcher et al., 2015; NSC, 2019).

\section{Fatigue Countermeasures}

The most effective fatigue mitigation is adequate sleep (Lee \& Kim, 2018; Salazar, n.d.). According to ICAO (2016), sleep is not a commodity that could be traded off in order to increase the amount of time available for waking activities. Both quantity of sleep and quality sleep are paramount for restoring the waking function of persons. Acute sleep loss and/or cumulative sleep debt can pose a high-risk to aviation safety. Several studies have addressed factors which can effect sleep. For instance, pilots should avoid large and/or inadequate meals and caffeine a few hours of bedtime (CASA, 2012; ICAO, 2016). The establishment of a pre-bed routine can help the body fall asleep. According to Caldwell et al. (2009) and Petrie et al. (2004), controlled napping prior to a duty (especially a night duty), and even during the flight (if permitted and safe) could restore alertness and improve reaction speed, with a positive impact on aviation safety. Napping is one of the most effective non-pharmacological strategy to enhance the pilot's situational awareness (Caldwell et al., 2009; Rosekind et al., 1994). However, aviators should be cautious with the risks associated with sleep inertia (Caldwell et al., 2009; ICAO, 2016, 2016).

Empirical data also indicate that regular exercise is an effective fatigue countermeasure (National Health Services, 2019; Rosekind et al., 1994). The health benefits of regular exercise include increased protection from heart disease, stroke, high blood pressure, noninsulin-dependent diabetes, obesity, back pain, stroke, and osteoporosis (Biddle, Fox, \& Boutcher, 2000; CASA, 2012; Williamson \& Pahor, 2010). In addition to the physical and psychological health benefits, exercise can improve sleep, thus help mitigate fatigue. Exercise can have a beneficial impact even on aviators' circadian rhythms, and their ability to adapt to a new time zone (Caldwell et al., 2009). Nevertheless, pilots should consider the time and/or amount of exercise when determining its effectiveness as a fatigue countermeasure. Stimulants are another option to combat fatigue but again should be used with caution.

Caffeine, an addictive drug, is frequently used as the first strategy by pilots to mitigate fatigue (Caldwell et al., 2009). Caffeine can be found in different plants (e.g., coffee beans, cocoa nuts), and in several beverages and food products, such as cola drinks and chocolate. Previous studies indicated that caffeine improves performance in cases of sleep deprivation (Bonnet \& Arand, 1994a, 1994b; Caldwell et al., 2009; Jay, Petrilli, Ferguson, Dawson, \& Lamond, 2006; 
O'Callaghan, Muurlink, \& Reid, 2018; Reyner \& Horne, 2000). Pilots should use caffeine judiciously in order to reduce the impact of fatigue. For example, caffeinated products should not be used when fatigue is not an issue in order to prevent body-tolerance to caffeine. Additionally, flight crews should avoid caffeine a few hours before bedtime. As a stimulant, caffeine may compromise a good quality sleep (ICAO, 2016).

Other factors, such as inadequate food, can make pilots to feel sluggish, weary, and more tired. Pilots may not be aware of the effect of low blood sugar level on their ability to stay alert (CASA, 2012). Yet, considering what pilots eat and the time they eat before going to bed may have a negative impact on their sleep quantity and quality. On the other hand, inadequate or failure to eat may not be conducive to a restful sleep (Caldwell et al., 2009). A study by Roky et al., (2003) suggested that intermittent fasting can disrupt sleepiness. Findings of a study by Roky, Chapotot, Hakkou, Benchekroun, and Buguet (2001) indicated that intermittent fasting during Ramadan impairs the quantity and quality of sleep. Therefore, flight crews should maintain a balanced diet and an adequate routine for their meals (CASA, 2012).

The use of prescription and over-the-counter medications within the aviation systems has received a lot of attention recently (Caldwell, 2001; Caldwell \& Caldwell, 2016; Caldwell et al., 2001; CASA, 2012; ICAO, 2012; Petrie, Powel, \& Broadbent, 2004). For example, a study by Caldwell (2001) suggested that the use of modafinil and dextroamphetamine can sustain the performance and situational awareness of sleep-deprived aviators. Previous research studies have also indicated that the use of melatonin could help aviation professionals overcome jet lag and shift lag in aviation operations (Arendt, Deacon, English, Hampton, \& Morgan, 1995; Caldwell, 2005; ICAO, 2016; Zhdanova, 2005). Aviators should be cautious with possible side-effects, interactions with other drugs, and the impact on aviation safety as a whole while using stimulants and/or sleep aids. Considering the impact medications could have in aviation safety (CASA, 2012), Caldwell and Caldwell (2016) recommended aviators should consult with their aviation medical examiner or flight surgeon before using these drugs.

Pilot's impairment due to inadequate sleep and/or fatigue cannot be overcome by education and training (Caldwell, 2001; Dawson \& McCulloch, 2005; Dinges, 1995; Watson et al., 2015). Fatigue can negatively impact the most experienced pilots. However, training and education, in agreement with the safety management systems (SMS) pillars (ICAO, 2013, 2018), is vital to mitigating fatigue in operational environments (Caldwell et al., 2009, Rocco \& Nesthus, 2005). Pilots should receive formal training addressing causes of and factors that increase fatigue, the dynamics of sleep loss and quality sleep, the effects of the circadian rhythms on the body clock, and fatigue countermeasures, among other topics. The benefits of training and education for aviation safety have been described by DeFusco, Unangst, Cooley, and Landry (2015), ICAO (2018), Junior et al. (2009), and Stolzer and Goglia (2016).

As previously noted, fatigue is associated with multiple factors (Avers, 2011; ICAO, 2016). Moreover, the way persons identify and/or cope with fatigue generally vary (Caldwell \& Caldwell, 2016; ICAO, 2016; NSC, 2019; Petrie, 2004). Fatigue cannot be successfully overcome with a single strategy, such as training and education. In fact, solutions are not straightforward (Dawson, 2012; Dawson et al, 2017). According to Dawson and McCullouch (2005), and Fletcher et al. (2015), an effective approach to fatigue management in the flight deck requires a variety of risk 
mitigation strategies involving multiple stakeholders, including pilots. Studies addressing fatigue mitigation frequently occur in a laboratory setting, thus they may not work as well in the aviation environment (Fletcher et al., 2015). Adequate quantity and good quality sleep are likely the most effective way to reduce fatigue (NSC, 2019; Salazar, n.d.; Watson et al., 2015). However, other strategies can contribute to this process (Caldwell et al., 2009; CASA, 2012; ICAO, 2012). Most research studies addressing fatigue in aviation have either involved commercial pilots (Gander et al., 2013; Goode, 2003; Honn et al., 2016; Petrie \& Dawson, 1997; Petrie, Powell, \& Broadbent, 2004; Powel et al., 2007) or military pilots (Caldwell, 2001; Caldwell \& Brown, 2003; Caldwell, Gilreath, Stephen, Erickson, \& Smythe, 2000; Miller \& Melfi, 2006). Little to nothing has been done involving the GA community. There are some differences across aviation operations involving different operators. However, both commercial, military, and GA pilots are constantly confronted with early arrivals, night flights, long-duty hours (frequently well before the flight), multi-segment flights, 24/7 operations, and cross-meridian flights. The causes and symptoms of fatigue are consistent across an array of aviation operations (Avers \& Johnson, 2011; Caldwell, 2005; Caldwell \& Caldwell, 2016). Therefore, strategies to identify the symptoms of fatigue as well as some aviators' countermeasures to mitigate fatigue could be applicable to those three aviation environments.

\section{Fatigue in Flight Training Environments}

Flight schools, a significant portion of the general aviation community (McDale \& Ma, 2008), are the cradle of the aviation industry (MacKinnon, 2004). The FAA oversees all flight training in the U.S. in accordance with the regulations laid out in 14 CFR Parts 61, 141, or 142 (FAA, 2016). Certificated Code of Federal Regulations (CFR) Part 141 flight schools must meet stringent standards for ground and flight training, maintenance, personnel, aircraft, and facilities. (Electronic Code of Federal Regulations, Title 14, Chapter I, Subchapter H, Part 141, 2018). These strictures help to ensure a high-level of aviation efficiency and safety (Mendonca \& Carney, 2017). Several studies (Buboltz, Brown, \& Soper, 2001; Hicks \& Pellegrini, 1991; Jean-Louis, Von-Gizycki, Zizi, \& Nunes 1998; Lack, 1986) have investigated problems associated with sleep deprivation among university students. Empirical evidence indicates that several factors affect the sleep-wake pattern of college students, including delayed bed time, academic and social demands, reduced total sleep time, erratic academic schedules, part-time jobs (Jean-Louis et al., 1998). Poor sleep habits can significantly impair students' academic performance. Most importantly, as mentioned earlier, insufficient and/or inadequate sleep are the most influencing factors on fatigue (Caldwell, 2005; NSC, 2019; Watson, 2015).

Students in a collegiate aviation environment are more subjective to the insidious and detrimental effects of fatigue. Thus, fatigue is a potentially threat to the safety of pilots involved with flight instruction activities (Keller et al., 2019; McDale \& Ma, 2008). Several factors, alone or in combination, can increase the levels of fatigue by pilots in a collegiate aviation environment, such as:

1. Intensive workload and/or long workday;

2. Flight(s) rescheduled due to poor weather (or any unexpected) conditions; 
3. Early flights;

4. Flights following a demanding night preparing for examinations;

5. Early flights followed by night flights;

6. Family issues;

7. Social activities;

8. Complex maneuvers by inexperienced student pilots; and

9. Night flights after a long day of academic and/or social activities.

To increase self-awareness of prominent aviation human factors issues, the FAA (2016) has recommended the use of the "IMSAFE checklist to determine physical and mental readiness for flying" (p. 2-8). The "I" stands for illness, the " $M$ " is for medication, the " $S$ " represents stress, the "A" stands for alcohol, the " $F$ " stands for fatigue, and the "E" represents emotion. However, pilots in a collegiate aviation environment could not use this checklist properly, could not realize the onset of fatigue, could not have a sound understanding on the consequences of fatigue on the quality and safety of their flights, or any combination of these conditions (Keller et al., 2019; McDale \& Ma, 2008). The identification of the factors currently leading to pilots' fatigue in a collegiate flight school, as well as the strategies used by those pilots (if any) to mitigate such safety hazard, is paramount for aviation safety. Yet, they can warrant academic interventions (Buboltz et al., 2001), education and training programs targeting those pilots (Caldwell et al., 2009, Rocco \& Nesthus, 2005; Stolzer \& Goglia, 2016), and new policies by aviation stakeholders (ICAO, 2016) leading to enhanced safety. The purpose of this study is threefold:

1. To evaluate Collegiate aviation students' self-awareness of their fatigue issues;

2. To investigate possible causes of fatigue afflicting Collegiate aviation students;

3. To investigate the collegiate aviation students' lifestyle and perceptions of personal solutions to fatigue.

\section{Method}

\section{Participants}

Title 14 CFR Part 141 programs are FAA approved and periodically audited by the Agency. According to the FAA (2016), enrollment in a 14 CFR Part 141 program will ensure quality, safety, efficiency, and continuity due to a structured approach to flight training. The target population for this study consisted of a subset of the GA community, flight instructors and students from an accredited Code of Federal Regulations (CFR) Part 141 flight training and four-year degree-awarding university in the Midwestern region of the United States. Those collegiate aviation students, all pilots, frequently pursue a career as an air carrier or a corporate pilot. In 
addition, they typically earn their private and commercial pilot as well as flight instructor certificates within four years. Pilots were eligible to participate in this study if they were at least 18 years old, directly involved with the University Professional flight program, and if they had flown in the previous six months. It is important to note that in a university environment, electronic devices are easily accessible, thus ensuring that the target population would have the means to participate in a web-based survey. The population for this study was limited to approximately 350 pilots from both settings from which researchers could draw a sample.

\section{Procedures}

The researchers developed a survey questionnaire based upon previous studies and documents by major aviation stakeholders addressing fatigue identification and management. The survey was composed of four sections:

\section{Fatigue awareness;}

2. Causes of fatigue;

3. Lifestyle; and

\section{Demographics.}

The survey questions were presented in different formats, including five-point Likert rating scales, rank-order, and open-ended. A pilot test of survey was conducted with six faculty members who teach aviation related courses at the target University, and with 10 certified flight instructors from the same university. Researchers asked them to review the assessment instrument for organization, grammar, appropriateness, and syntax (Borg \& Gall, 1989; Sartori, 2009). Researchers then made the necessary modifications, following their suggestions. After making the necessary modifications to the survey questionnaire, researchers conducted a beta test with 24 flight students. The fatigue awareness subscale consisted of eight items $(\alpha=.755)$, the causes of fatigue subscale consisted of 11 items $(\alpha=.747)$, and the lifestyle subscale consisted of 7 items $(\alpha$ $=.763$ ). The Collegiate Aviation Fatigue Inventory (CAFI) was found to be acceptably reliable (26 items; $\alpha=.754$ ) during the beta test and the researchers moved forward without further revisions (Field, 2009).

Participants were provided one open-ended question in each of the four first sections of the CAFI questionnaire. Those three open-ended questions were designed as an attempt to allow pilots to provide creative answers that would increase the amount and enhance the quality of information needed to achieve the goals of this research project. The open-ended questions were expected to provide qualitative information that could assist the researchers to explain the quantitative findings in more detail. According to Patton (2015), qualitative data can increase the quality, strength, and credibility of a research study.

After the IRB approval, researchers started the study processes. An invitation letter was sent by email to prospective participants with a link to the CAFI questionnaire. There was a statement in the beginning of the survey questionnaire explaining the purpose of the study, the 
study specific procedures, the estimated time to complete the survey questionnaire, possible risks and benefits regarding the study, the anonymous and confidential aspects of the study, and the participants' rights. Additionally, prospective participants were informed that they would be eligible to enter their names into a draw for one of three US\$50.00 gift certificates. The survey questionnaire was distributed through the Qualtrics ${ }^{\circledR}$ web-based survey software to all participants. The survey questionnaire link stayed live from August 28 ${ }^{\text {th }}, 2018$ to November $5^{\text {th }}, 2018$. While the survey was live, two reminder emails were sent out.

Responses to the online survey questionnaire were captured on a secure Qualtrics® server. Data on Qualtrics ${ }^{\circledR}$ were accessed, transcribed, and processed using password protected computer accounts. The analysis of data captured was conducted using codes developed by the researchers (e.g., code "A" refers to flight instructors who hold a commercial pilot certificate). Most importantly, researchers did not triangulate data in any way to make it easy to identify participants. Results will be presented without identifiable information. The data will be kept on file indefinitely for research purposes.

\section{Data Analysis}

Descriptive statistics were used in order to have a better understanding about the quantitative data. It is important to note that throughout the assessment tool, participants were asked open-ended questions that provided qualitative data. Qualitative data could add depth and details to qualitative data. The analysis of qualitative data can also provide information that cannot be measured, thus, illuminating what the numbers mean. Qualitative data was analyzed using a content analysis method, and a deductive to inductive approach. Initially, we investigated the extent the responses to the open-ended questions supported or illuminated existing theories, sensitizing concepts and explanations, and/or results of previous studies. Alongside with this approach, we used an inductive analysis concept for the identification of possible new themes and possible explanations (Patton, 2015).

\section{Results}

\section{Factor Analysis}

The Collegiate Aviation Fatigue Inventory (CAFI) was a mixed methods survey to examine fatigue issues among collegiate aviation flight students and instructors. Within the CAFI there were three sections that utilized Likert scales: fatigue awareness, fatigue causes, and lifestyle. An Exploratory Factor Analysis (EFA) (Principal Axis Factoring) was conducted on each sub-scale using a varimax rotation. There were eight items in the fatigue awareness subscale, 11 items within the fatigue causes sub-scale, and seven items in the lifestyle sub-scale. The researchers used the following conditions to for extraction decisions. Strongly loaded items on each factor was identified using the scree plot of the SPSS $®$ output by retaining all factors before the line levels off, and under the following conditions:

1. Communalities less than 0.4 .

2. Eigen values greater than 1 . 
The factors and percentage of variance explained by the Eigen values were determined. After the factors were extracted, the reliability of the scales was determined using the Cronbach's Alpha test in SPSS®. Generally, for social sciences, an alpha $(\alpha)$ of .70 and above indicates high internal consistency (Fields, 2009). Initial testing and inspection of the correlation matrix showed that all variables had at least one correlation coefficient greater than 0.3 . The overall Kaiser-Meyer-Olkin (KMO) measure was 0.778, with individual KMO measures all greater than 0.6. This classified the scales as mediocre according to Kaiser (1974). Bartlett's Test of Sphericity was statistically significant $(\mathrm{p}<.0005)$, indicating that the data was likely factorable.

The first run of the test produced eighth factors which had Eigen values above 1.0. These factors explained approximately $67.5 \%$ of the variance. However, the researchers decided to force extraction and reduce the factors to three based on the scree plot and interpretive outcomes. The scree plot can be found in Appendix B. Because of forcing a reduction to three factors, the level of variance explained was reduced to $51.559 \%$.

After the forced extraction, the Fatigue Awareness (FA) scale yielded a one-factor solution with approximately $28.671 \%$ of the variances explained by the initial Eigen values. Items fatigue awareness 1-8 loaded strongly on a single factor. A reliability analysis was

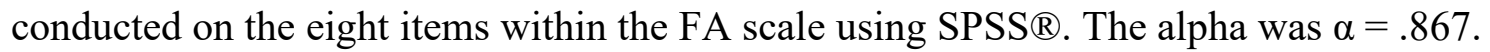
Additional results indicated no improvement if any of the items were removed.

In the Fatigue Causes (FC) scale, the factor analysis yielded a one factor solution. Items fatigue_causes one and seven were removed due to weak loading and the analysis was rerun. The new result yielded the same one-factor solution. However, one item indicated weak loading. Therefore, it was removed, and the analysis was rerun. The new explained variance was $12.833 \%$. A reliability analysis was conducted on the remaining eight item FC scale and resulted in an alpha of $\alpha=.793$. Additional results indicated no improvement if any of the items were removed.

In the Lifestyle Scale, the factor analyses yielded a one factor solution. Items lifestyle four, six, and seven indicated weak loading. Therefore, these items were removed, and the analysis was rerun. The new result yielded the same one-factor solution. However, lifestyle five indicated weak loading. Therefore, it was removed, and the analysis was rerun. The new explained was $10.05 \%$. A reliability analysis was conducted on the three remaining Lifestyle scale items and resulted in an alpha of $\alpha=.734$. Additional results indicated no improvement if any of the items were removed.

All the items that were retained in the various scales after the factors extraction and reliability analysis were summed and used for further analysis. The descriptive statistics on the summed scales was conducted and the results were determined to be consistent with the assumptions of a normally distributed data. The assumption of normality was confirmed based on histograms with normality plot as well as the kurtosis and skewness values of the descriptive statistics tables. The values were in the acceptable range of -1 to +1 . See Appendix A for the rotated factor matrix after extraction. 


\section{Demographics}

The target population consisted of 350 pilots enrolled in the professional flight program of the university in the Midwestern region of the United States. Participants needed to be at least 18 years old and have flown in the last six months. Based on a $28 \%$ response rate, researchers expected 98 responses. Between August and November 2018, 126 survey attempts were recorded, which represents a $42 \%$ response rate. However, not all sections of the study were completed by respondents.

Participants' demographics and flight experience information was obtained as a part of the study. This information included age, gender, flight ratings and hours, and enrollment status (see Tables 1 and 2). Four participants did not complete this part of the CAFI questionnaire. Approximately $93 \%$ of the respondents were in the 18-25 years old range, and only one participant was in the 46-55 years old range. Among the participants, 96 were males, 25 females, and one preferred not say. Eighty-three pilots $(65 \%)$ reported they had less than 250 total logged flight time. About 25\% of the respondents had logged between 250 and 500 flight hours, and only eight participants reported they had logged between 500 and 1,000 flight hours. Findings indicated that the majority of pilots did not have a high level of flight experience.

Table 1

Summary of Participant Demographic Information

\begin{tabular}{ccc}
\hline \multicolumn{3}{c}{ Age } \\
\hline $18-25$ & 113 & $92.62 \%$ \\
$26-35$ & 6 & $4.92 \%$ \\
$36-35$ & 2 & $1.64 \%$ \\
$46-55$ & 1 & $0.82 \%$ \\
Total & 122 & \\
\multicolumn{3}{c}{ Certifications and Ratings Frequencies } \\
\hline Student Pilot & 57 & $17.43 \%$ \\
Private & 82 & $25.08 \%$ \\
Commercial & 53 & $16.21 \%$ \\
Instrument & 58 & $17.74 \%$ \\
CFI & 29 & $8.87 \%$ \\
CFI-Instrument & 6 & $1.83 \%$ \\
Multi-Engine & 29 & 8.87 \\
Multi-Engine Instrument & 0 & 0 \\
Airline Transport Pilot & 1 & $0.31 \%$ \\
Remote Pilot & 12 & $3.67 \%$ \\
\hline & 22 & $18.03 \%$ \\
\hline Freshman & Enrollment Status & $22.95 \%$ \\
Sophomore & 32 & $26.23 \%$ \\
Junior & 26 & $21.31 \%$ \\
Senior & 8 & $6.56 \%$ \\
Graduate Student & 3 & $2.46 \%$ \\
Combined Degree Program & 3 & $2.46 \%$ \\
Other & &
\end{tabular}


Table 2

Certificates \& Ratings $X$ Levels of Enrollment

\begin{tabular}{|c|c|c|c|c|c|c|c|c|}
\hline $\begin{array}{c}\text { Certificates \& } \\
\text { Ratings }\end{array}$ & Freshman & Sophomore & Junior & Senior & $\begin{array}{l}\text { Graduate } \\
\text { Student }\end{array}$ & $\begin{array}{c}\text { Combined } \\
\text { Degree } \\
\text { Program }\end{array}$ & Other & Total \\
\hline Student & 15 & 11 & 12 & 12 & 5 & 1 & 1 & 57 \\
\hline Private & 12 & 27 & 18 & 19 & 3 & 2 & 1 & 82 \\
\hline Commercial & 0 & 2 & 21 & 24 & 2 & 3 & 1 & 53 \\
\hline Instrument & 0 & 3 & 24 & 24 & 2 & 3 & 2 & 58 \\
\hline Multi-Engine & 0 & 0 & 5 & 21 & 1 & 1 & 1 & 29 \\
\hline CFI & 0 & 0 & 10 & 16 & 1 & 1 & 1 & 29 \\
\hline CFI-I & 0 & 0 & 0 & 5 & 0 & 0 & 1 & 6 \\
\hline MEI & 0 & 0 & 0 & 0 & 0 & 0 & 0 & 0 \\
\hline ATP & 0 & 0 & 0 & 1 & 0 & 0 & 0 & 1 \\
\hline Remote Pilot & 1 & 2 & 2 & 5 & 1 & 0 & 1 & 12 \\
\hline Total & 22 & 28 & 32 & 26 & 8 & 3 & 3 & 122 \\
\hline \multicolumn{9}{|l|}{ Logged Flight } \\
\hline Less than 250 & 21 & 27 & 19 & 8 & 6 & 1 & 1 & 83 \\
\hline $250-500$ & 1 & 1 & 12 & 13 & 1 & 2 & 1 & 31 \\
\hline $501-1000$ & 0 & 0 & 1 & 5 & 1 & 0 & 1 & 8 \\
\hline Total & 22 & 28 & 32 & 26 & 8 & 3 & 3 & 122 \\
\hline
\end{tabular}

Note. Certified flight instructor (CFI).

Note 2. Certified flight instructor - instrument (CFII).

Note 3. Multi-engine instructor (MEI).

Note 4. Airline transport pilot (ATP).

The first section of the survey questionnaire contained eight questions, and was designed to evaluate collegiate aviation students' self-awareness of their fatigue issues (see Table 3 for the Fatigue Awareness Questions). Respondents were presented scenarios that would indicate that fatigue could have had a negative effect during flight activities. One hundred and twenty-six participants completed this section of the study. Approximately $44 \%$ of the participants reported that they agreed to a certain degree (sometimes, often, and always) that they had fallen asleep or struggled to stay awake during flight activities. Additionally, 53\% of the respondents somewhat agreed that they had not frequently given their best effort because of being fatigued. See Figure 1 for Fatigue Awareness Survey items frequencies.

\section{Table 3}

Fatigue Awareness Questions (Q1)

\begin{tabular}{|c|c|}
\hline Questions & $\begin{array}{l}\text { Section 1 - Fatigue Awareness } \\
\end{array}$ \\
\hline Q1.1 & I have fallen asleep or struggled to stay awake during a training flight. \\
\hline Q1.2 & $\begin{array}{l}\text { I have remarked (out loud or to myself) about how tired I was, but proceeded to go on the } \\
\text { training flight anyway. }\end{array}$ \\
\hline Q1.3 & $\begin{array}{l}\text { To my knowledge, I have overlooked mistakes I have made during the training flight because of } \\
\text { reduced awareness or judgment due to fatigue. }\end{array}$ \\
\hline Q1.4 & I have felt a disinterest during flight training because I was fatigued. \\
\hline Q1.5 & Sometimes I have not given my best effort because of being fatigued. \\
\hline Q1.6 & To my knowledge, I have made mistakes during a training flight because I was fatigued. \\
\hline Q1.7 & I have felt heightened irritation during a training flight because I was fatigued. \\
\hline Q1.8 & My abilities to carry out tasks requiring concentration have been decreased due to fatigue. \\
\hline
\end{tabular}




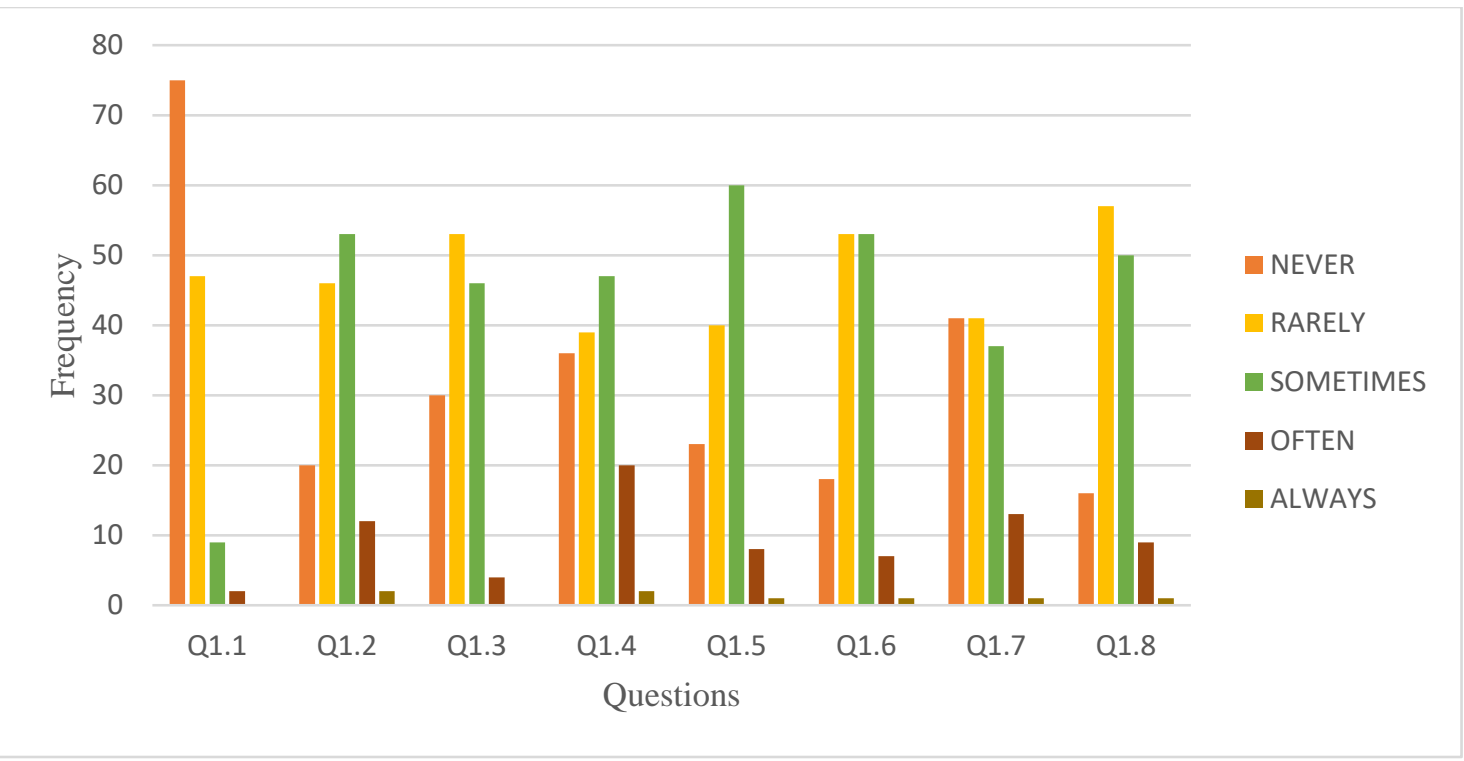

Figure 1. Responses to the Fatigue Awareness Questions

Note: 1 = Never; 2 = Rarely; $3=$ Sometimes; 4 = Often; $5=$ Always

Responses to open-ended questions can illuminate systemic issues. Moreover, they are appropriate for situations in which a detailed understanding of a phenomena that has not been adequately studied is necessary (Patton, 2015). In section one pilots were asked about what symptoms would cause them to realize they were fatigued. Survey responses are provided "as is" and in some cases may include grammatical and spelling errors. One-hundred and eighteen participants answered this question. We grouped the participants' responses into five themes, as suggested by Petrie and Dawson (1997): cognitive dysfunction, somatic symptoms, subjective tiredness states, and behavioral changes. The participants' responses generally fell under two or more of these constructs.

Seventy-three participants reported cognitive dysfunction as a symptom of fatigue. Quoting one participant, "slow reaction time, inability to perform at best ability". Another participant stated "feeling flat \& not having situational awareness as good as when I am not fatigued". One participant mentioned that he/she "skips checklist items, fails to properly follow the checklist items, missed radio calls, and in general a lack of situational awareness" when fatigued. Those findings are in agreement with previous studies that provided evidence of increasing levels of fatigue with decrements in alertness and cognitive function, including impaired task performance and increases in errors (Caldwell, 2005; Czeisher et al., 2016; Dawson et al., 2012; Dawson \& McCulloch, 2005; Petrie et al., 2004). Some of the participants' answers are as follows:

"Zoning out, tunnel vision, not paying attention to instruments";

"Struggling to be actively alert, slow reactions";

"Slower reaction time; lower situational awareness; heavy eyes"; 
"Simple tasks like holding direction become difficult"; and

"Skipping checklist items, failure to properly follow the checklist, missed radio calls, and in general a lack of situational awareness".

Sore eyes, sore muscles, low energy (Petrie \& Dawson, 1997), micro sleeps, eye rubbing, headache, and exhaustion (CASA, 2012) are among the somatic effects of fatigue. Twenty-three participants noticed they usually have somatic symptoms when fatigued. One respondent stated that he/she feels "brain foggy ness and muscle soreness". Quoting another participant, "I have a headache, decisions requiring concentration become difficult, I struggle to keep my eyes open". Some of the participants' answers are as follows:

"Grogginess, heavy eyes, trouble focusing";

"Repetitive yawning, headache, some pain behind the eyes"; and

"My eyes become very droopy and hurt".

Fatigue is a subjective experience. Fatigue measurements can be based on pilots' recall or current symptoms of fatigue, especially subjective sleepiness (ICAO, 2016). Fifty-three participants noted they feel they are sleepy when fatigued. One participants cited "fighting to keep my eyes open, inability to focus, and frequent yawning". Quoting another participant, "yawning, struggling to stay awake, eyes difficult to keep open, confused, euphoric, making mistakes". CASA (2012) and ICAO (2016) have suggested that mood and comportment changes such as irritable and bad-tempered behavior with colleagues, nervousness, and restlessness, could be symptoms of fatigue. One participant stated that irritation is a sign that he/she is fatigued. Another participant argued he/she gets frustrated, stressed, and irritated easily when fatigued. Quoting one participant, "I feel sluggish, irritated very easily". Another participant stated, "feeling lazy to teach, short tempered (not willing to put up with many errors of student".

The second section of the survey questionnaire contained initially 11 questions, but three were eliminated due to weak loading (see Table 4 for the Causes of Fatigue questions). This section was designed to evaluate how collegiate aviation students rank factors that had contributed to fatigue during flight training. Participants were presented different conditions empirically known to cause fatigue (Caldwell, 2005; Lee \& Kim, 2018; McDale \& Ma, 2008). One-hundred and twenty-six participants completed this section of the study. The great majority of respondents $(84.12 \%)$ indicated that "working a long day" is the major factor that (sometimes, often, and always) contributed to their fatigue during flight training. Almost $81 \%$ of the participants indicated that "not enough sleep" is also an important factor that caused them to be fatigued during flight activities. Fifty-four percent of the respondents indicated that "poor scheduling of academic classes" had never or rarely contributed to fatigue during flight training. See Figure 2 for the Causes of Fatigue Survey items frequencies.

Table 4

Causes of Fatigue Questions (Q2)

\begin{tabular}{ccc}
\hline Questions & Section 2 - Causes of Fatigue \\
Q2.1 Working a long day. &
\end{tabular}


Q2.2 Stress caused by family or other psychological conditions.

Q2.3 Poor scheduling of flight lessons (e.g., too early, too late, or too many).

Q2.4 Poor scheduling of academic classes.

Q2.5 Personal activities or other commitments (e.g. 2nd job).

Q2.6 Academic activities (e.g. midterms, student organizations, etc).

Q2.7 Quality of sleep (restlessness or interrupted sleep).

Q2.8 Not of enough sleep.

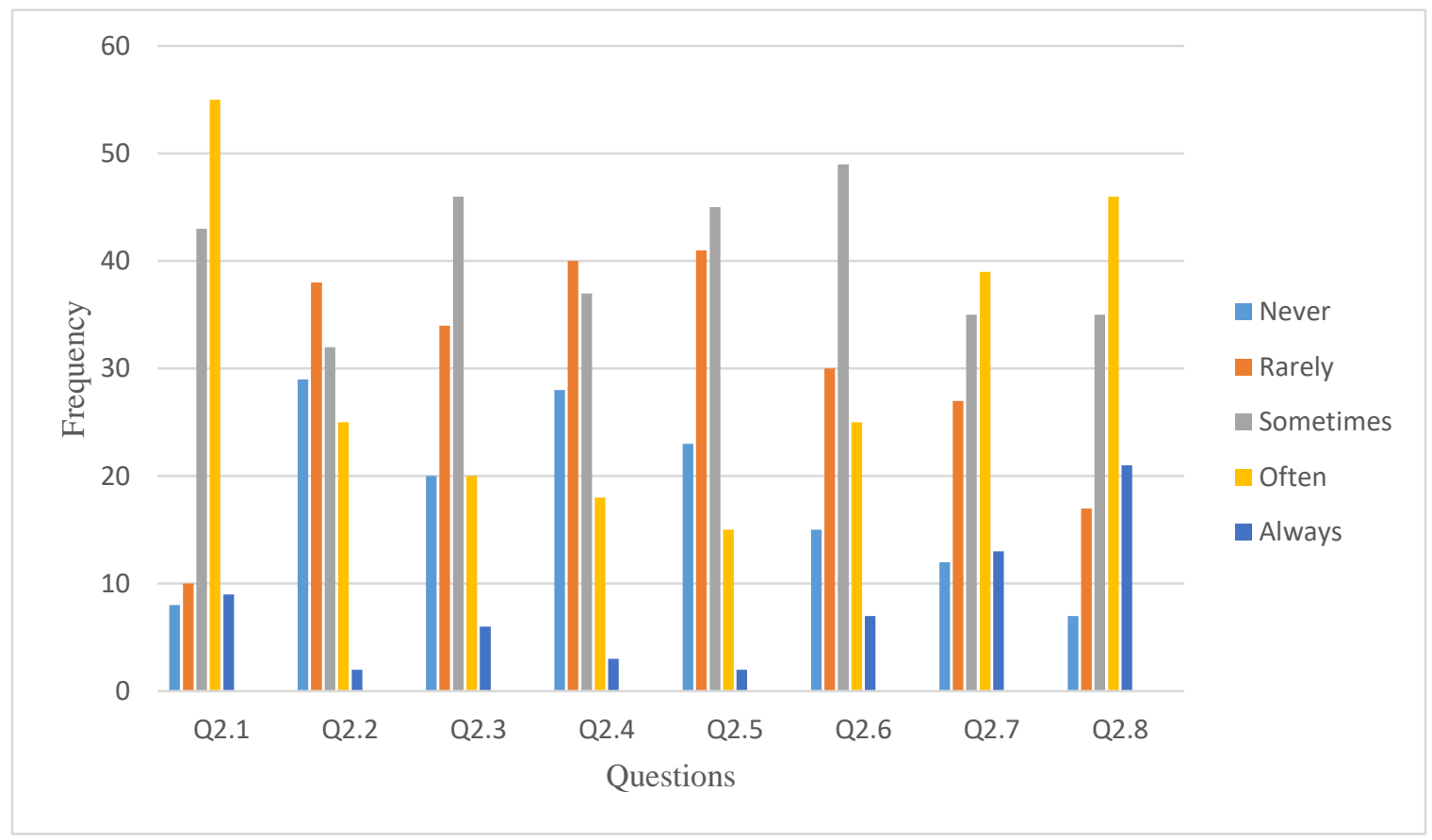

Figure 2. Responses to the Causes of Fatigue Questions

Note: 1 = Never; 2 = Rarely; 3 = Sometimes; 4 = Often; $5=$ Always

Inadequate sleep quantity and quality are the major factors that determine fatigue (Czeisher et al., 2016). However, those issues do not fully represent all possible contributing factors that can cause fatigue, especially during flight activities. Crew scheduling, the aircraft environment, circadian rhythms (Lee \& Kim, 2018), excessive workload, age, general health, and inadequate food and fluid intake could also cause fatigue (CASA, 2012). In section two of the study participants were encouraged to provide further comments on other factors that contributed to fatigue during their flight activities. Thirty-one students answered this part of the questionnaire. Twelve respondents cited workload as a contributing factor to fatigue. Quoting on participant, "excessively long days 24+ hours of continued activity, strenuous training/working out". One participant indicated that "being a student athlete is like working a full time job on top of being a student in flight". Inadequate food and fluid intake were also factors mentioned by seven respondents. Quoting one participant, "dehydration". Another participant stated "proper nutrition". Poor sleep quality and/or quantity was cited by four participants. Quoting one respondent, "I think in general for me it can be hard to sleep if I'm thinking about a big flight the 
next day (long xc, stage check, check ride, or even the last few flights leading up to a check). It's the kind of anticipation knowing that I need to be on my A game to make the flight count that can keep me up". Stress related to academic activities was a factor mentioned by three participants. One respondent stated, "stress of school and work. Other factors leading to fatigue included stress, lack of physical activities, and poor academic scheduling.

According to CASA (2012), positive lifestyle choice, that includes good sleeping habits, physical activities, a balanced diet, and the use of effective time management strategies are behaviors that could help mitigate fatigue. The third section of the survey questionnaire contained initially seven questions, but four were eliminated due to weak loading (see Table 5 for the Lifestyle questions). This section presented statements designed to evaluate how collegiate aviation students describe their lifestyles. These statements reflected empirical strategies that could help mitigate fatigue. The participants' responses could range from "strongly disagree" to "strongly agree". One hundred and twenty-five pilots answered this part of the survey questionnaire. Ninety-one participants agreed to some level that they had a healthy work and academic life balance. Approximately $49.6 \%$ of the respondents indicated that they maintain a proper and healthy diet. However, only $45.6 \%$ of the participants indicated that they exercise regularly. Empirical evidence supports the mental and health benefits of physical activity and exercise (Eriksen \& Bruusgaard, 2004; Penedo \& Dahn, 2005), including as a fatigue mitigation strategy (CASA, 2012). See Table 5 and Figure 3 for Lifestyle Survey items frequencies.

Table 5

Lifestyle Statements (Q3)

\begin{tabular}{cl}
\hline Questions & \multicolumn{1}{c}{ Section 3 - Lifestyle } \\
\hline Q3.1 & I have a healthy work/academic life balance. \\
Q3.2 & I exercise regularly. \\
Q3.3 & I maintain a proper and healthy diet. \\
\hline
\end{tabular}

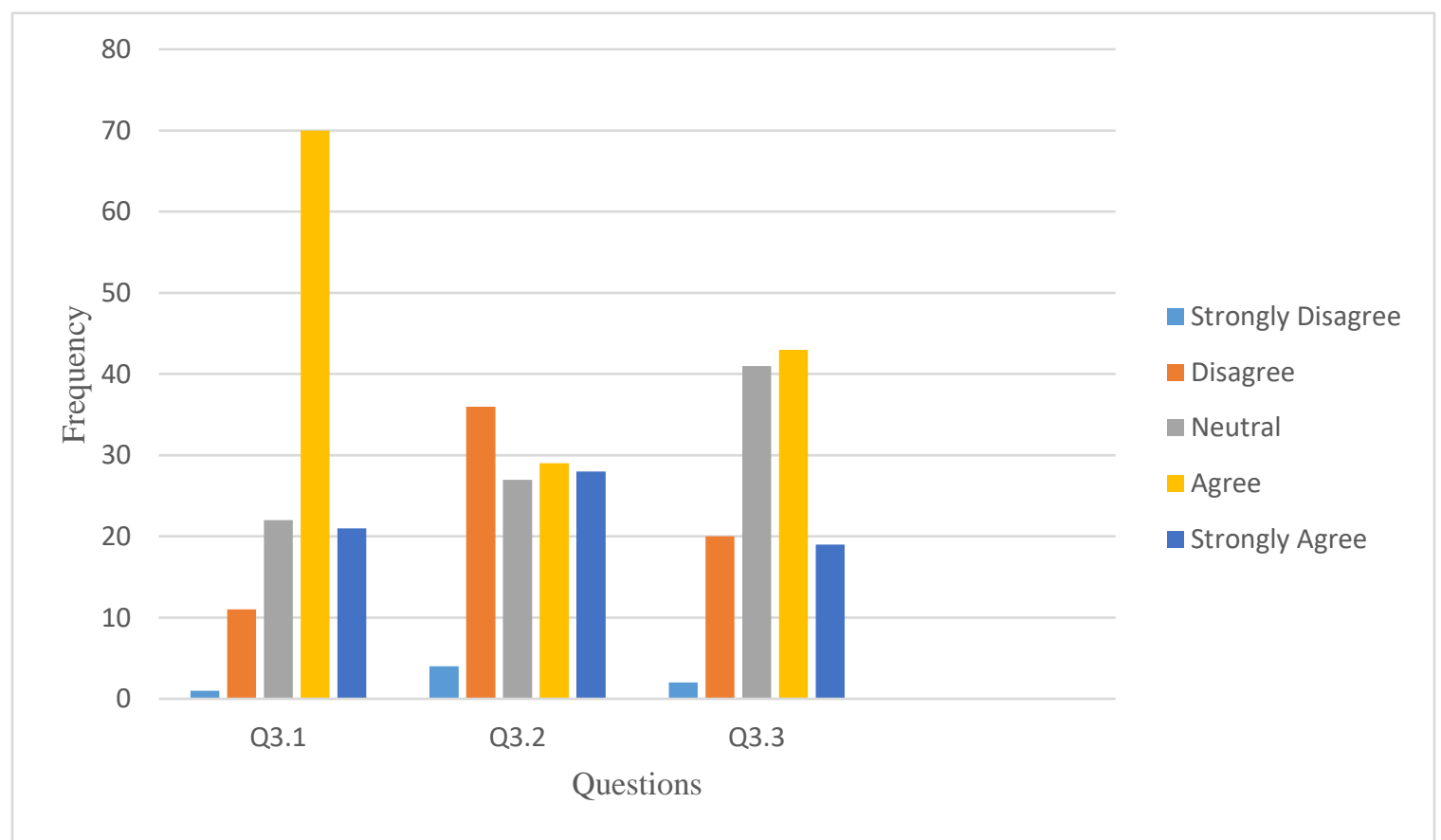


Figure 3. Responses to the Lifestyle Questions

Note: 1 = Strongly Disagree; 2 = Disagree; $3=$ Neutral; $4=$ Agree $; 5=$ Strongly Agree

Sufficient sleep is paramount for wellbeing and optimal work performance. Quality sleep can be affected by different conditions, such as sleep disorders, circadian rhythms, fluid and food intake prior to bed time, and shift work (CASA, 2012). In section three of the survey questionnaire, students were given an opportunity to indicate the most significant factors inhibiting their quality and quantity of sleep. Ninety four participants completed this section. Their responses indicated different factors, alone or in combination, that generally inhibit their sleep quantity and quality. Forty-eight participants, for example, suggested high-workload, academic and flight schedules, and stress may affect their sleep. Quoting one participant, "it is my schedule. Between work, flight, and school, I usually have to stay up until midnight every night, and then I have to be up by 7am at the latest for my classes the next day". Another participant stated, "I am taking too many credit hours, I can never sleep, I always work". Another participant stated "academic workload limits quantity. Stress limits quality". Eighteen participants mentioned issues with their bed environments that disrupted their bed time. Quoting one respondent, "ambient noise, room temperature and mental state". Some of the participants' answers are as follows:

"Varying schedules between roommates causes there to be louder than average noise during sleeping hours",

"Loud neighbors;

"Being involuntarily placed in on campus housing with three other people who all sleep in the same room". And

"Temperature of the room, too hot or too cold".

Sixteen participants stated that the use of electronic devices until late could inhibit their sleep quality and quantity. Quoting one participant, "heat during the night and on my phone too long. I also think about many things at night as well". Some of the participants' answers are as follows:

"Cell phone usage, watching TV late at night, being busy during the day so my online free time is late at night so I stay up later";

"Watching youtube videos and using my phone in bed", and

"Using phone before bed".

Ten participants cited caffeine or alcohol prior to bed, social commitments, or poor time management as factors that inhibit the quantity and quality of their sleep. Quoting one participant, "friends wanting to hang out at late hours while I have work and classes early, mainly due to opposite schedules". One participant stated, "caffeine" while other cited "alcohol". 


\author{
"Talking to parents"; \\ "I think I stay up too late hanging out with my friends; and
}

"Homework and social activities".

\title{
Discussion and Conclusions
}

To date, there has been little research on fatigue in pilots in a collegiate aviation environment if compared with commercial and military aviation. The purpose of this study was threefold: to assess collegiate aviation students' self-awareness of their fatigue issues; to investigate causes of fatigue afflicting those students; and to probe their lifestyle. Participants were recruited from an accredited CFR Part 141 flight training and four-year degree-awarding university in the Midwestern region of the United States. Findings suggested that most participants (68\%) had logged less than 250 flight hours, and approximately seven percent had between 500 and 1,000 flight hours, and no participant had more than 1,000 flight hours. Therefore, most participants did not have a lot of flight experience. Students reported they held flight certificates and ratings that ranged from student pilot to airline transport pilot, which included several combinations (e.g., CFI- instrument and multi-engine instrument). Approximately $49 \%$ of the participants were either sophomore or junior students, and $93 \%$ of them were between 18 to 25 years old.

The results concerning the participants' awareness of their fatigue issues shed some light in previous studies by Caldwell et al. (2009), Dawson and Reid (1997), Goode (2003), NSC (2019), Roach et al. (2017), and Stokes and Kite (2016). For instance, responses suggested that fatigue has played a major role during flight training activities (Stokes \& Kite, 2016). Even though $92 \%$ of the participants indicated they had rarely or never fallen asleep or even struggled to stay awake during flight training, $51 \%$ of them had at least a few times proceeded with flight activities despite being extremely tired. Moreover, almost $78 \%$ of those pilots had overlooked mistakes they made during flight training because of impaired judgement and situational awareness due to fatigue. A finding of concern was that $46 \%$ of those pilots acknowledged they had made mistakes during flight activities because of being fatigued. The majority of respondents $(53 \%)$ indicated they had not given their best effort during flight training because of fatigue. Flying fatigued can degrade the performance of cognitive tasks (Czeisher et al., 2016), alertness (Goode, 2003), and produce levels of impairment similar to high levels of alcohol intoxication (Dawson \& Reid, 1997).

Qualitative data can provide in-depth detail of systemic issues as well as more opportunities to glean insights from quantitative data (Patton, 2015). The majority (59\%) of the participants' responses revealed that cognitive dysfunction symptoms, such as reduced situational awareness and/or slow thoughts during flight activities, were factors that indicated they were fatigued. One participant mentioned memory loss and inability to focus as manifestation of fatigue. Forty-one percent of their responses also suggested that subjective tiredness states, such as feeling lazy or low in energy were factors that indicated they were fatigued. It is important to note that several responses included at least two factors, as suggested by Petrie and Dawson (1997).

Several factors could cause fatigue during flight training in a collegiate environment, including inadequate sleep (CASA, 2012; Czeisher et al., 2016; Tefft, 2016), family and social 
factors (Lee \& Kim, 2018), sustained periods of wakefulness (Avers \& Johnson, 2011), part-time jobs, and academic commitments (Jean-Louis et al., 1998). Mental and physical fatigue, resulting from working for prolonged periods was the main contributing factor of fatigue during flight training cited by participants. Respondents also indicated that inadequate sleep (quantity and/or quality) were the second most important factor causing fatigue during flight activities. Interestingly, approximately $65 \%$ of the participants indicated that academic activities were fatigue causal factors during flight activities. All those factors can cause fatigue during flight training in different ways, and all of them could be interrelated and/or related to other factors. Improvements in those factors, such as using prescriptive models (Dawson \& McCulloch, 2005), and better lifestyle practices (CASA, 2012; ICAO, 2012) could enhance the safety of the Part 141 environment. In addition, training and education, as suggested by Caldwell (2005), Dawson et al. (2012), and McCulloch et al. (2003), could help create a safety culture key to addressing fatigue in such aviation environment. Ultimately, pilots and those responsible or accountable for the flight activities must have the knowledge and skills to mitigate this insidious threat to aviation safety (Mendonca \& Carney, 2017).

Fatigue is a multidimensional construct resulting from one to several factors combined, including inadequate sleep, long duty periods, excessive workload, and circadian rhythms (Caldwell et al., 2009). Part 141 pilots are subject to additional factors, such as sleep deprivation (Buboltz et al., 2001; Hicks \& Pellegrini, 1991; Jean-Louis et al., 1998; Lack, 1986), intensive academic schedules, and inadequate nutrition and fluid intake that alone or in combination can cause fatigue (CASA, 2012). The most effective way to combat fatigue is adequate sleep (Dawson \& McCulloch, 2005; Salazar, n.d.). However, pilots must make efforts to create a healthy lifestyle that could not only benefit their general well-being and health, but also help prevent and/or mitigate the effects of fatigue (CASA, 2012). Approximately $73 \%$ of the participants indicated they had a healthy and work academic life. Empirical data have indicated the benefits of physical exercise, including reduced feelings of fatigue, stress, and low energy (O'connor \& Puetz, 2005; Puetz, 2006) strengthened immune function and better digestion (CASA, 2012), and enhanced sleep quality and quantity (Caldwell et al., 2009). It is important to consider the timing and levels of physical exercise if engaging with physical activities close to bed time (Morin, 2006). Nevertheless, physical exercise is a more effective and healthier choice than energy drinks, over-the-counter or prescribed drugs, and caffeine. Another finding of concern was that the majority of respondents either disagreed to some level (32\%) or were neutral $(21.6 \%)$ regarding exercising regularly. Interestingly, in section two of the survey almost $47 \%$ of the participants agreed to some level that stress was a contributing factors to fatigue they felt during flight activities. Moreover, approximately $70 \%$ and $81 \%$ of the participants indicated that quality and quantity of sleep, respectively, were also causal factors of fatigue during flight activities. Therefore, it could be assumed that regular physical activities by Part 141 pilots can help mitigate the causes and symptoms of fatigue during flight activities.

Biological, social, and behavioral factors could disrupt sleep patterns. Caldwell et al. (2009) provides suggestions of strategies that could optimize the quality and quantity of sleep (e.g., avoid caffeine and energetics intake few hours before bedtime). CASA (2012) recommends persons should avoid playing with computers or watching televisions while on their bedroom since those can disrupt their sleep. The most cited factors by participants were high academic workload, the utilization of electronic devices prior to bed, and issues related to their dorms (e.g., noise; inadequate room temperature). 
In conclusion, fatigue is a safety hazard in a collegiate environment that needs addressing. Systematic fatigue education and training, better lifestyle practices, effective workload management, and even a prescriptive approach could significantly enhance aviation safety and the well-being of student pilots. This study is the first of a series whose general goals are to evaluate collegiate aviation students' self-awareness of their fatigue issues, impact of fatigue on flight training quality and safety, and potential solutions. Based on the current findings, the next report will investigate the participants' aeronautical decision-making process using fatigue-related scenarios. In addition, another study will investigate the pilots' subjective level of sleepiness and fatigue at particular times during the day using the Karolinska Sleepiness Scale (ICAO, 2016; Kaida et al., 2006) and the Samn-Perelli Scale (ICAO, 2016; Samn \& Perelli, 1982), respectively. It is recommended that future studies targeting fatigue identification and management by Part 141 flight schools target a larger population of different organizations. In addition, future studies could utilize inferential statistics procedures as an attempt to identify differences between participants with different flight ratings and or levels of enrollment.

\section{Limitations}

The current study experienced some limitations. The 'true' response rate for this study was difficult to determine, as the number of questionnaires returned represented $36 \%$ of those sent out. Nevertheless, receiving responses from over 122 participants was a reasonable achievement, given the relatively sensitive nature of the issue. Nine participants were 26 years old or older, probably non-traditional students, which could also have biased the findings of this project. Another possible limitation of this project was the validity and reliability of the questions used in the CAFI questionnaire. However, researchers used rigorous scientific processes to enhance its reliability and validity. There were also limitations associated with survey research, such as non-response and representativeness of the population of interest (Leedy \& Ormrod, 2015). The desired participants profile included experienced pilots with different flight experience, ranging from a few to more than 1000 flight hours. Researchers attempted to recruit such pilots by allowing Part $141 \mathrm{GA}$ aviators with different flight experiences, flight certificates, and ratings to participate in the study. However, $65 \%$ of the participants had logged less than 250 flight hours and only nine percent of them held a certified flight instructorinstrument rating. However, the researchers supported the quantitative findings of this study with a robust literature review and used qualitative data to illuminate the findings retrieved from the analysis of quantitative data. The limitations of this project may constrain the generalizability of the results. Nevertheless, the findings can still provide the groundwork for the development and implementation of aviation stakeholders' efforts to mitigate the risk of fatigue during flight training. 


\section{References}

Arendt, J., Deacon, S., English, J., Hampton, S., \& Morgan, L. (1995). Melatonin and adjustment to phase shift. Journal of Sleep Research, 4(2), 74-79.

Australia Government Civil Aviation Safety Authority (2012). Fatigue management strategies for aviation workers: A training and development workbook. Retrieved from https://www.casa.gov.au/files/fatigue-management-strategies-aviation-workers-training-anddevelopment-workbook

Avers, K., \& Johnson, W. (2011). A review of Federal Aviation Administration fatigue research: Transitioning scientific results to the aviation industry. Aviation Psychology and Applied Human Factors, 1(2), 87-98.

Biddle, S., Fox, K., \& Boutcher, S. (2000). Physical activity and psychological well-being. London, New York: Routledge.

Bonnet, M. H., \& Arand, D. L. (1994a). Impact of naps and caffeine on extended nocturnal performance. Physiology \& Behavior, 56(1), 03-9.

Bonnet, M. H., \& Arand, D. L. (1994b). The use of prophylactic naps and caffeine to maintain performance during a continuous operation. Ergonomics 37(6), 1009-1020.

Borg, W. R., \& Gall, M. D. (1989). Educational research. White Plains, NY: Longman.

Buboltz, W. C., Brown, F., \& Soper, B. (2001). Sleep habits and patterns of college students: A preliminary study. Journal of American College Health, 50(3), 131-35.

Caldwell, J. A. (2001). Efficacy of stimulants for fatigue management: The effects of Provigil@ and Dexedrine ${ }^{\circledR}$ on sleep-deprived aviators. Transportation Research Part F: Traffic Psychology and Behaviour, 4, 19-37.

Caldwell, J. A. (2005). Fatigue in aviation. Travel Medicine and Infectious Disease 3(2), 85-96.

Caldwell, J. A., \& Brown, C. L. (2003). Running' on empty? "Go Pills," fatigue and aviator safety. Flying Safety, 59(3), 4.

Caldwell, J. A., \& Caldwell, J. L. (2016). Fatigue in aviation: A guide to staying awake at the stick. NY: Routledge.

Caldwell, J. A, Gilreath, S. R., Stephen R., Erickson, B. S., \& Smythe, N. K. (2000). Is fatigue a problem in army aviation: The results of a survey of aviators and aircrews (USAARL Report No. 200103). Retrieved from https://pdfs.semanticscholar.org/ aaf5/a8fc7b317e026262a89bc60022018dac30ce.pdf

Caldwell, J., L., Hall, K. K., Prazinko, B. F., Norman, D. N., Rowe, T., Erickson, B. S., ... Caldwell, J. A. (2001). The efficacy of temazepam for improving daytime sleep and night-time performance in army aviators (USAARL Report No. 2002-05). Retrieved from http://www.dtic.mil/dtic/tr/fulltext/u2/a397776.pdf 
Caldwell, J. A., Mallis, M. M., Caldwell, J. L., Miller, J., Paul, M., \& Neri, D. (2009). Fatigue countermeasures in aviation. Aviation, Space, and Environmental Medicine 80(1), 28-59.

Civil Aviation Safety Authority (CASA). (2012). Fatigue management strategies for aviation workers: A training \& development workbook. Retrieved from https://www.casa.gov.au/files/fatiguetoolkitstrategiespdf

Czeisler, C. A., Wickwire, E. M., Barger, L. K., Dement, W. C., Gamble, K., Harterbaum, N., ...Hirshkowitz, M. (2016). Sleep-deprived motor vehicle operators are unfit to drive: A multidisciplinary expert consensus statement on drowsy driving. Sleep Health, 2(2): 94-99

Dawson, D., Chapman, J., \& Thomas, M. J. W. (2012). Fatigue-proofing: A new approach to reducing fatigue-related risk using the principles of error management. Sleep Medicine Reviews 16: 167175.

Dawson, D., Cleggett, C., Thompson, K., \& Thomas, M. J. W. (2017). Fatigue proofing: The role of protective behaviours in mediating fatigue-related risk in a defence aviation environment. Accident Analysis and Prevention 99: 465-68.

Dawson, D., \& McCulloch, K. (2005). Managing fatigue: It's about sleep. Sleep Medicine Reviews 9(5); $365-380$.

Dawson, D., \& Reid, K. (1997). Fatigue, alcohol and performance impairment. Nature, 388(6639), 235 235.

DeFusco, R. P., Junior, E. T. U., Cooley, T. R., \& Landry, J. M. (2015). Applying an SMS approach to wildlife hazard management (ACRP Report No. 145). Retrieved from the Transportation Research Board on the National Academies website: http://www.trb.org/Publications/Blurbs/173318.aspx

Dinges, D. (1995). An overview of sleepiness and accidents. Journal of Sleep Research, 4, 4-14.

Eriksen, W., \& Bruusgaard, D. (2004). Do physical leisure time activities prevent fatigue? A 15 month prospective study of nurses' aides. British Journal of Sports Medicine, 38(3), 331-336.

Federal Aviation Administration (FAA). (2016). Pilot's handbook of aeronautical knowledge. Retrieved from https://www.faa.gov/regulations_policies/handbooks_manuals/aviation/phak/

Field, A. (2009). Discovering statistics using SPSS. London: Sage.

Fletcher, A., Hooper, B., Dunican, I., \& Kogi, K. (2015). Fatigue management in safety-critical operations: History, terminology, management system frameworks, and industry challenges. Reviews of Human Factors and Ergonomics, 10(1), 6-28.

Gander, P. H., Mangie, J., Signal, T. L., Berg, M. J. V. D., Mulrine, H. M., Jay, S. M., Mangie, J. (2013). In-flight sleep, pilot fatigue and psychomotor vigilance task performance on ultra-long range versus long range flights. Journal of Sleep Research, 22(2), 697-706. 
Gawron, V. J. (2016). Overview of self-reported measures of fatigue. The International Journal of Aviation Psychology, 26(3), 120-131.

Goode, J. (2003). Are pilots at risk of accidents due to fatigue? Journal of Safety Research, 34(3), 309313.

Greeley, H. P., Roma, P. G., Mallis, M. M., Hursh, S. R., Mead, A. M., \& Nesthus, T. E. (2013). Field study evaluation of cepstrum coefficient speech analysis for fatigue in aviation cabin crew (DOT/FAA/AM-13/19). Retrieved from the FAA website: https://www.faa.gov/data_research/ research/med_humanfacs/oamtechreports/2010s/media/201319.pdf

Heinrich, H. W., \& Granniss, E. R. (1959). Industrial accident prevention: A scientific approach. New York: McGraw-Hill.

Hicks, R., \& Pellegrini, R. (1991). The changing sleep habits of college students. Perceptual and Motor Skills, 72(3_suppl), 1106.

Hirshkowitz, M., Whiton, K., Alessi, C., Bruni, O., Hazen, N., Herman, J., Adams, H. P. J., ... Ware, J. C. (2016). National Sleep Foundation's updated sleep duration recommendations: Final report. Sleep Health, 1(4): 233-243.

Honn, A. K. (2017, March). How fatigue increases accident risk: Evidence and theories. Paper presented at the $10^{\text {th }}$ International Conference on Managing Fatigue, San Diego, CA. Retrieved from https://fatigueconference2017.com/materials/thursday-am/causation/Honn.pdf

Honn, A. K., Satterfield, B. C., McCauley, P., Caldwell, J. L., \& Van-Dongen, H. P. A. (2016). Fatiguing effect of multiple take-offs and landings in regional airline operations. Accident Analysis and Prevention, 86, 199-208.

International Civil Aviation Organization (ICAO). (2003). Training guidelines for aircraft accident investigators (Cir 298 AN/172). Montreal, Canada: Author.International Civil Aviation Organization (ICAO). (2016). Fatigue risk management systems (Doc. 9966). Montreal, Canada: Author.

International Civil Aviation Organization (ICAO). (2012). Manual of civil aviation medicine (Doc. 8984AN/895) ( $3^{\text {rd }}$ ed.). Montreal, Canada: Author.

International Civil Aviation Organization (ICAO). (2013). Annex 19 to the Convention on International Civil Aviation, Safety Management ( $1^{\text {st }}$ ed.). Montreal, Canada: Author.

International Civil Aviation Organization (ICAO). (2016). Fatigue risk management systems: Manual for regulators (Doc. 9966). Montreal, Canada: Author.

International Civil Aviation Organization (ICAO). (2018). ICAO safety management manual (Doc. 9859) ( $4^{\text {th }}$ ed.). Montreal, Canada: Author.

Jay, S. M., Petrilli, R. M., Ferguson, S. A., Dawson, D., \& Lamond, N. (2006). The suitability of a caffeinated energy drink for night-shift workers. Physiology \& Behavior, 87(5), 925-931. 
Jean-Louis, G., Von-Gizycki, H., Zizi, F., \& Nunes, J. (1998). Mood states and sleepiness in college students: Influences of age, sex, habitual sleep, and substance Use. Perceptual and Motor Skills, $87(2), 507-512$.

Junior, M. A., Shirazi, H., Cardoso, S., Brown, J., Speir, R., Seleznev, O., . . McCall, E. (2009). Safety management systems for airports (ACRP Report No. 01, volume 2). Retrieved from the Transportation Research Board on the National Academies website: http://www.trb. org/main/blurbs/162491.aspx

Kaida, K., Takahashi, M., Åkerstedt, T., Nakata, A., Otsuka, Y., Haratani, T., \& Fukasawa, K. (2006). Validation of the Karolinska sleepiness scale against performance and EEG variables. Clinical Neurophysiology, 117(7), 1574-1581.

Keller, J., Mendonca, F. A. C., Levin, E., \& Teo, A. (2019, May). Fatigue risks in aviation: An exploratory study with collegiate aviation pilots. Paper presented at the International Symposyum on Aviation Psychology, Dayton, OH.

Lack, L. C. (1986). Delayed sleep and sleep loss in university students. Journal of American College Health, 35(3), 105-10.

Leedy, P. D., \& Ormrod, J. L. (2015). Practical research: Planning and design. Harlow, England: Pearson Education Limited.

Lee, S., \& Kim, J. K. (2018). Factors contributing to the risk of airline pilot fatigue. Journal of Air Transport Management, 67, 197-207.

Marcus, J. H., \& Rosekind, M. R. (2017). Fatigue in transportation: NTSB investigations and safety recommendations: Injury Prevention. Journal of the International Society for Child and Adolescent Injury Prevention, 23(4), 232-238. doi:10.1136/injuryprev-2015-041791

McDale, S., \& Ma, J. (2008). Effects of fatigue on flight training: A survey of U.S. Part 141 flight schools. International Journal of Applied Aviation Studies, 8(2), 311-336.

MacKinnon, B. (2004). Sharing the skies manual: An aviation industry guide to the management of wildlife hazards. Retrieved from the Government of Canada, Transport Canada website: https://www.tc.gc.ca/eng/civilaviation/publications/tp13549-menu-2163.htm

Mendonca, F. A. C., \& Carney, T. Q. (2017). A safety management model for FAR 141 approved flight schools. Journal of Aviation Technology and Engineering, 6(2), 33-49.

Miller, J. C., \& Melfi, M. L. (2006). Causes and effects of fatigue in experienced military aircrew. (AFRL-HE-BR-TR271). Retrieved from http://www.dtic.mil/dtic/tr/fulltext/u2/a462989.pdf

National Health Services (2019). Self-help tips to fight tiredeness. Retrieved from https://www.nhs.uk/live-well/sleep-and-tiredness/self-help-tips-to-fight-fatigue/

National Safety Council (2019). Fatigue. Retrieved from https://www.nsc.org/work-safety/safetytopics/fatigue/physiology-map 
National Transportation Safety Board (NTSB) (2009). Aviation database. Retrieved from https://www.ntsb.gov/_layouts/ntsb.aviation/index.aspx

National Transportation Safety Board (NTSB) (2019a). NTSB 2019-2020 most wanted list of transportation improvements. Retrieved from https://www.ntsb.gov/safety/mwl/Pages/default.aspx

National Transportation Safety Board (NTSB) (2019b). Aviation accident database \& synopses. Retrieved from https://www.ntsb.gov/_layouts/ntsb.aviation/index.aspx

O'Callaghan, F., Muurlink, O. \& Reid N. (2018). Effects of caffeine on sleep quality and daytime functioning. Risk Management and Healthcare Policy, 11(2018), 263-71.

O'connor, P. J., \& Puetz, T. W. (2005). Chronic Physical Activity and Feelings of Energy and Fatigue. Medicine \& Science in Sports \& Exercise, 37(2), 299-305.

Patton, M. Q. (2015). Qualitative research \& evaluation methods. London, United Kingdom: SAGE Publications, Inc.

Penedo, F. J., \& Dahn, J. R. (2005). Exercise and well-being: A review of mental and physical health benefits associated with physical activity. Current Opinion in Psychiatry, 18(2), 189-193.

Petrie, K., \& Dawson, A. (1997). Symptoms of fatigue and coping strategies in international pilots. The International Journal of Aviation Psychology, 7(3), 251-258.

Petrie, K., Powell, D., \& Broadbent, E. (2004). Fatigue self-management strategies and reported fatigue in international pilots. Ergonomics, 47(5), 461-468.

Powell, D., Spencer, M., Holland, D., Broadbent, E., \& Petrie, K. (2007). Pilot fatigue in short-haul operations: Effects of number of sectors, duty length, and time of day. Aviation, Space, and Environmental Medicine, 78(7), 698-701.

Puetz, T. (2006). Physical activity and feelings of energy and fatigue. Sports Medicine, 36(9), 767-780.

Reyner, L. A., \& Horne, J. A. (2000). Early morning driver sleepiness: Effectiveness of $200 \mathrm{mg}$ caffeine. Psychophysiology, 37(2), 251-256.

Roach, D., Roberts, P., Dawson, D., Meuleners, L., Brook, L., \& Sargent, C. (2017). Controlling fatigue risk in safety-critical workplaces: A summary of selected papers from the 9th International Conference on Managing Fatigue in Transportation, Resources and Health. Accident Analysis and Prevention, 379-382

Rocco, P. S. D., \& Nesthus, T. E. (2005). Shiftwork and air traffic control: Transitioning research results to the workforce. In B. Kirwan, M. R. Rodgers, \& D. S. Schaefer (Eds.), Human factors impacts in air traffic management (pp. 243-278). Burlington, VT: Ashgate.

Roky, R., Chapotot, F., Hakkou, F., Benchekroun, M., \& Buguet, A. (2001). Sleep during Ramadan intermittent fasting. Journal of Sleep Research, 10(4), 319-327. 
Roky, R., Chapotot, F., Benchekroun, M., Benaji, B., Hakkou, F., Elkhalifi, H., \& Buguet, A. (2003). Daytime sleepiness during Ramadan intermittent fasting: Polysomnographic and quantitative waking EEG study. Journal of Sleep Research, 12(2), 95-101.

Rosekind, M. R., Graeber, R. C., Dinges, D. F., Connell, L., Rountree, M. S., Spinweber, C. L., \& Gillen, K. A. (1994). Crew factors in flight operations IX. Effects of preplanned cockpit rest on crew performance and alertness in long-haul operations (NASA Technical Memorandum 108839). Retrieved from the National Aeronautics and Space Administration website: https://ntrs.nasa.gov/search.jsp?R=19950006379

Salazar, G. J. (n.d.). Fatigue in aviation. Retrieved from the FAA website: https://www.faa.gov/pilots/ safety/pilotsafetybrochures/media/Fatigue_Aviation.pdf

Sartori, R. (2009). Face validity in personality tests: Psychometric instruments and projective techniques in comparison. Quality \& Quantity, 44(4), 749-759.

Samn, S. W., \& Perelli, L. P. (1982). Estimating aircrew fatigue: A Technique with application to airlift operations (Report SAM-TR- 82.21). Retrieved from https://archive.org/details/DTIC_ADA125319

Sieberichs, S., \& Kluge, A. (2016). Good sleep quality and ways to control fatigue risks in aviation-An empirical study with commercial airline pilots. In: Goonetilleke R., Karwowski W. (Eds) Advances in physical ergonomics and human factors. Advances in intelligent systems and computing, vol 489. doi:10.1007/978-3-319-41694-6_20

Stokes, A., \& Kite, K. (2016). Flight stress: Stress, fatigue and performance in aviation. New York: Routledge.

Stolzer, A. J., \& Goglia, J. (2016). Safety management systems in aviation. New York: Routledge.

Tefft, B. C. (2016). Acute sleep deprivation and risk of motor vehicle crash involvement. Retrieved from https://aaafoundation.org/acute-sleep-deprivation-risk-motor-vehicle-crash-involvement/

Watson N. F. et al. (2015). Recommended amount of sleep for a healthy adult: A joint consensus statement of the American Academy of Sleep Medicine and Sleep Research Society. Sleep, 38(6): 843-844.

Williamson, J., \& Pahor, M. (2010). Evidence regarding the benefits of physical exercise. Archives of Internal Medicine, 170(2), 124-125.

Wilson, K. (2015, August). Investigating human fatigue factors: A tale of two accidents. Paper presented at the International Society of Air safety Investigators conference, Augsburg, Germany.

Zhdanova, I. V. (2005). Melatonin as a hypnotic: Pro. Sleep Medicine Reviews, 9(1), 51-65.

\section{$\underline{\text { Appendix A }}$}


Rotated Factor Matrix with Varimax Rotation of the Three Fatigue Sub-Scales

\begin{tabular}{|c|c|c|c|}
\hline \multirow[t]{2}{*}{ Items } & \multicolumn{3}{|c|}{ Rotated Component Coefficients } \\
\hline & Factor 1 & Factor 2 & Factor \\
\hline fatigue_awareness5 & .763 & & \\
\hline fatigue_awareness4 & .712 & & \\
\hline fatigue_awareness6 & .698 & & \\
\hline fatigue_awareness2 & .654 & & \\
\hline fatigue_awareness7 & .639 & & \\
\hline fatigue_awareness3 & .632 & & \\
\hline fatigue_awareness8 & .620 & & \\
\hline fatigue_awareness1 & .472 & & \\
\hline fatigue_causes 9 & & .703 & \\
\hline fatigue_causes6 & & .636 & \\
\hline fatigue_causes 3 & & .574 & \\
\hline fatigue_causes5 & & .541 & \\
\hline fatigue_causes8 & & .516 & \\
\hline fatigue_causes 11 & & .499 & \\
\hline fatigue_causes 10 & & .477 & \\
\hline fatigue_causes4 & & .457 & \\
\hline lifestyle2 & & & .813 \\
\hline lifestyle3 & & & .716 \\
\hline lifestyle1 & & & .553 \\
\hline
\end{tabular}

\section{$\underline{\text { Appendix B }}$}




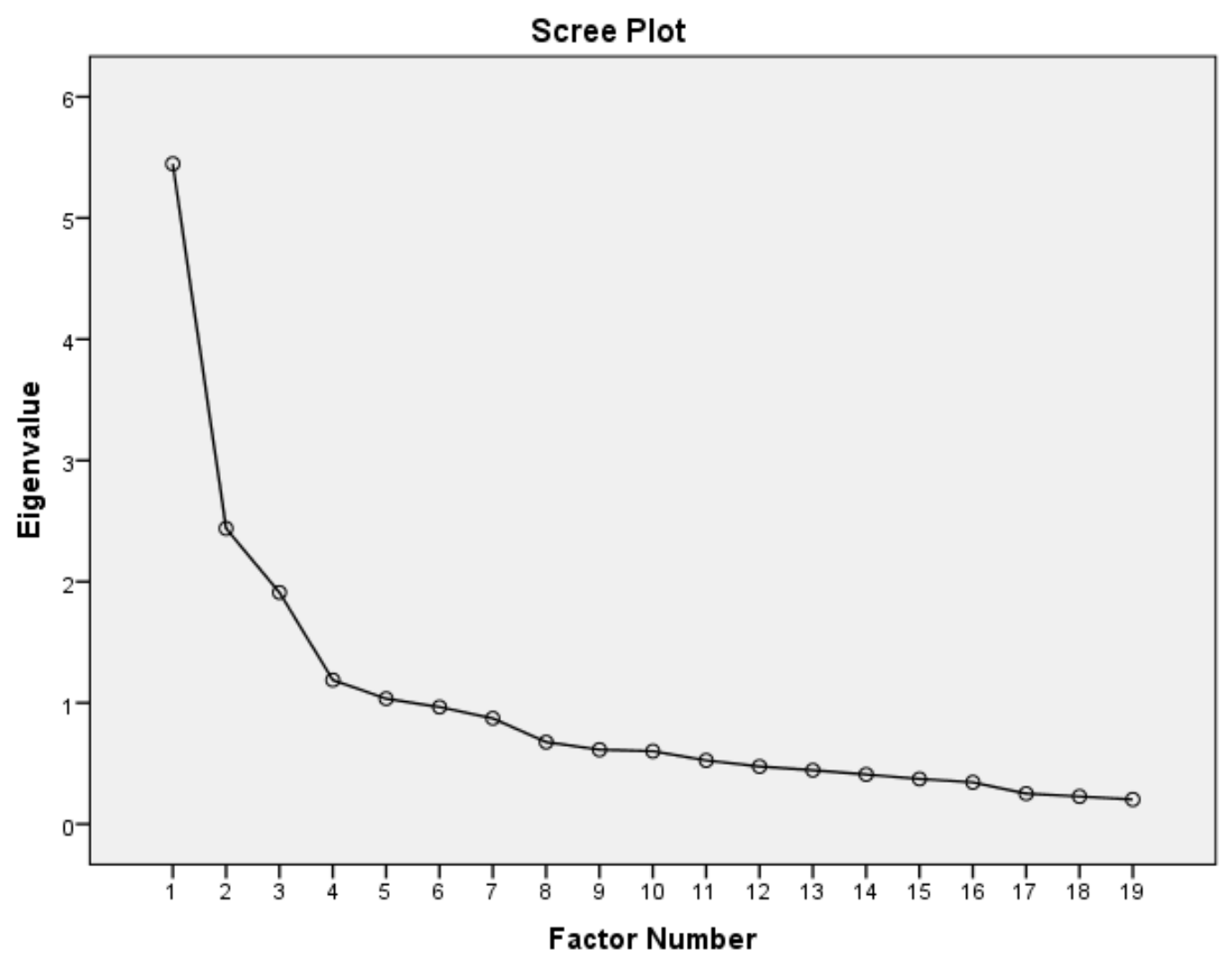

